\title{
Synthesis of Molybdenum Oxide Nanoparticles by Sol-Gel Method for Ammonia Gas Sensing
}

\author{
Bapurao G Bharate* \\ Department of Chemical and Biomolecular Engineering, Sogang University, 35 Baekbeom-r (Sinsu-dong), Mapo-gu, Seoul 121- \\ 742, Republic of Korea
}

*Corresponding author: Bapurao G Bharate, Department of Chemical and Biomolecular Engineering, Sogang University, 35

Baekbeom-r (Sinsu-dong), Mapo-gu, Seoul 121-742, Republic of Korea

\section{ARTICLE INFO}

Received: 幽 July 01, 2021

Published: 幽 July 13, 2021

Citation: Bapurao G Bharate. Synthesis of Molybdenum Oxide Nanoparticles by SolGel Method for Ammonia Gas Sensing. Biomed J Sci \& Tech Res 37(1)-2021. BJSTR. MS.ID.005957.

\section{ABSTRACT}

Molybdenium oxide nanoparticles were prepared by simple sol gel method using aliquat HTA-1 as surfactant for ammonia gas sensing. As synthesized sensor give good sensitivity and very good response. The synthesized MoO3 nanoparticles were characterized by using UV-Visible, XRD, SEM-EDS and TEM analysis techniques. TEM micrograph confirms the particle size is about $25 \mathrm{~nm}$ with layered structure. The particle size distribution shows the narrow size distubution which are well matches with calculated from XRD.

\section{Introduction}

Last several years much effort has been devoted to the study of molybdenum oxides and its related compound. Molybdenum oxide nanomaterials have attractive catalytic, photochromic and electronic properties, and a lot of potential applications in the areas of electrochemistry and sensing devices [1-5]. Molybdenum is a metal with a wide range of oxidation states from +2 to +7 existing in a variety of oxides. Molybdenum oxide is a potential material because of its wide range of stoichiometry and interesting behaviour which includes structural, chemical, electrical and optical, properties [6-9]. It exhibits a unique layer structure, which permits ion intercalation/deintercalation. Their properties strongly change as a function of oxygen vacancy concentration \& nonstoichiometry. As a wide band gap n type semiconducting materials, $\mathrm{MoO}_{3}$ has received considerable attention in many technological applications such as erasable optical storage media, optical switching coatings and high density memory devices, gas \& chemical sensors catalysis, energy efficient window technology, photochromic \& electrochromic devices [10-12].To date, molybdenum oxide nanomaterials were mainly synthesized by hydrothermal route ultrasonic, solvothermal and chemical vapour deposition methods [13-16]. However, in these processes, it took a long time to synthesize molybdenum oxide nanomaterials or the synthesis process required a high temperature. However, the reproducible preparation of small, stable $\mathrm{MnO}_{3}$ nanoparticles with tight size distribution is of immense importance and still remains a challenging task. Here in we report a simple route for the synthesis of $\mathrm{MoO}_{3}$ nanoparticles and its application for ammonia gas sensing.

\section{Experimental}

\section{Materials and General Methods}

Sodium molybadate, aliquat HTA-1 and ammonium hydroxide, Hydrochloric acid was purchased from Sigma Aldrich and used as received. The as prepared molybdenum oxide were characterized by UV-Visible, XRD, TEM, EDS techniques. The UV-Visible spectrum was recorded on spectrophotometer [JASCO 503]. The X-ray 
powder diffraction patterns were recorded on Bruker 8D advanced $\mathrm{X}$-ray diffractometer using $\mathrm{CuK} \alpha$ radiation of wavelength $=1.54056$ Å. TEM analysis was carried out with JEM 2000EXII /JEOL Ltd. (JAPAN) operated at $200 \mathrm{kv}$. In a typical procedure, $2 \mathrm{~g}$ of sodium molybdate was dissolved in $50 \mathrm{ml}$ of distilled water in a $250 \mathrm{ml}$ beaker to it add diluted solution of $2 \mathrm{ml}$ Aliquat HTA-1. Then to the above solution $5 \mathrm{ml}$ of hydrochloric acid was added drop wise with constant stirring for about 1 hours then adjust the temp at about $80^{\circ} \mathrm{C}$ for $1-2 \mathrm{~h}$. Then the final products Molybdenium oxide was obtained by heating above precipitate at $400^{\circ} \mathrm{C}$ for 4 hours. After the completion of the reaction, we get black colored powder of $\mathrm{MoO}_{3}$ nanoparticles in quantitative yield. The yield of $\mathrm{MoO}_{3}$ nanoparticles is about $86 \%$ which is quite good.

\section{Results and Discussion}

\section{Synthesis and Characterization}

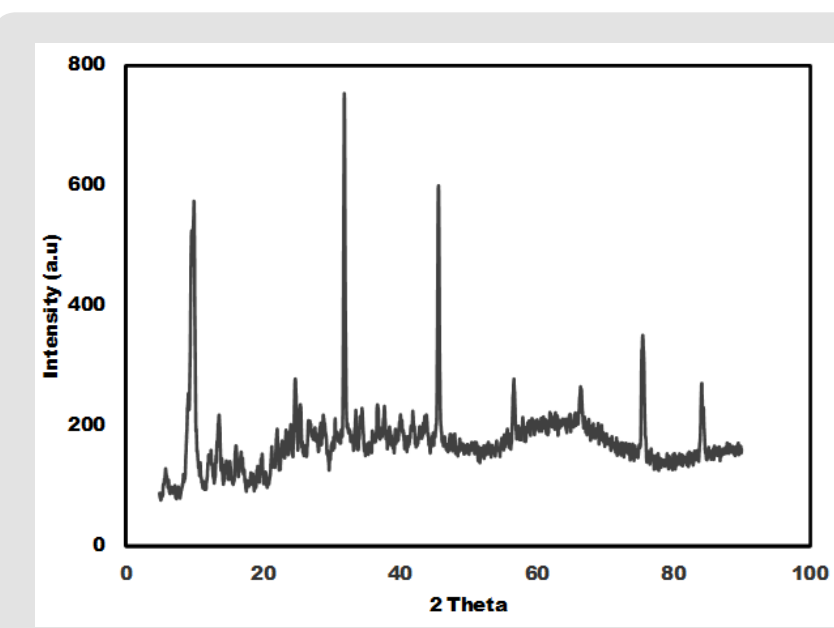

Figure 1: XRD of as-prepared $\mathrm{MnO}_{3}$ nanoparticles.

The as synthesized $\mathrm{MoO}_{3}$ nanoparticles was subjected to powder $\mathrm{x}$-ray diffraction analysis. A Cu k-alpha $\left(1.54 \mathrm{~A}^{\circ}\right)$ radiation was used with $2 \theta$ ranging from $6-90^{\circ}$. The X- ray diffraction pattern shown in Figure 1 explains the crystal structure and phase composition of $\mathrm{MoO}_{3}$ nanoparticles. The sharp diffraction peaks suggest crystalline nature of nanomaterials. The Figure 2 shows that the XRD peaks were observed at 10, 13.66, 24.82, 32.01, 45.72, 56.78, 66.48, 75.54, 84.22. The XRD analysis confirmed that the obtained product was $\mathrm{MoO}_{3}$ nanoparticles. The size and morphology of product were examined by transmission electron microscope (TEM). The TEM micrograph reveals that the size distribution of the nanoparticles was uniform. The size of the $\mathrm{MoO}_{3}$ nanoparticles was ranging from 20-25 nm. The morphological studies revealed that layered $\mathrm{MoO}_{3}$ is formed. Energy dispersive X-ray spectra were also recorded to determine the chemical composition of $\mathrm{MoO}_{3}$ nanoparticles. The uniform distribution and composition of the $\mathrm{MoO}_{3}$ nanoparticles was evaluated by energy dispersive X-ray spectroscopy. From EDS spectra one can obviously see that the signals of $\mathrm{O}$ and Mo elements appear in the EDX spectra, which further substantiates that the nanoparticles are composed of molybdenum oxide. The atomic ratio of Mo to 0 was measured to be 1:3, corresponding to the chemical composition of $\mathrm{MoO}_{3}$. The existence of $\mathrm{MoO}_{3}$ was also confirmed by the mapping of Mo and 0 signals. EDS mapping confirms the presence of Mo and oxygen in micrograph. The UV-visible spectrum of as synthesized $\mathrm{MoO}_{3}$ nanoparticles was recorded. The absorption spectrum exhibit the maximum absorption $\lambda$ max at $398 \mathrm{~nm}$. The prominent peak observed at $398 \mathrm{~nm}$ is due to absorption of surface plasmones. Particle size distribution studies have been carried out by dynamic light scattering techniques (DLS) via Laser input energy of $632 \mathrm{~nm}$. This is shown in Figure 3. It was observed that $\mathrm{MoO}_{3}$ Nanoparticles have narrow size distribution within the range of about 20-32 nm [17-20].

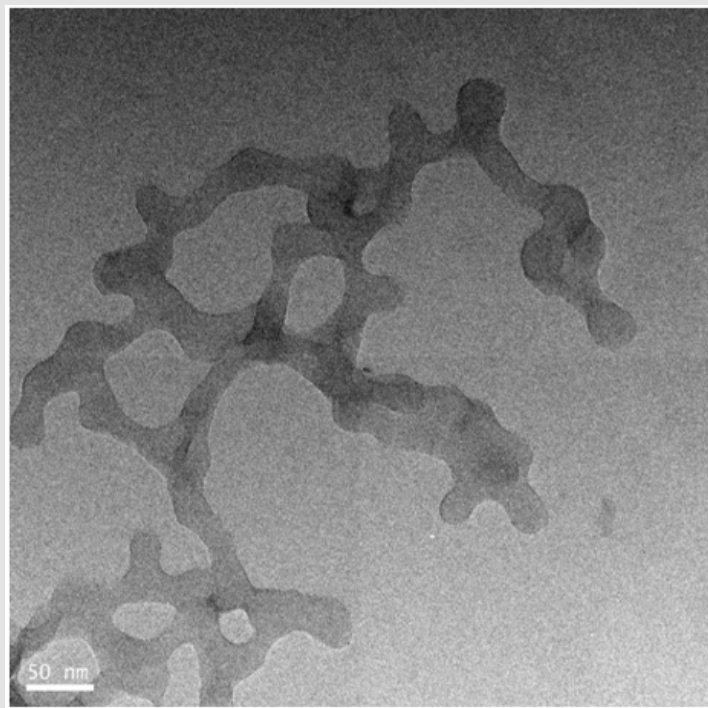

Figure 2: TEM images of as-prepared $\mathrm{MnO}_{3}$ nanoparticles.

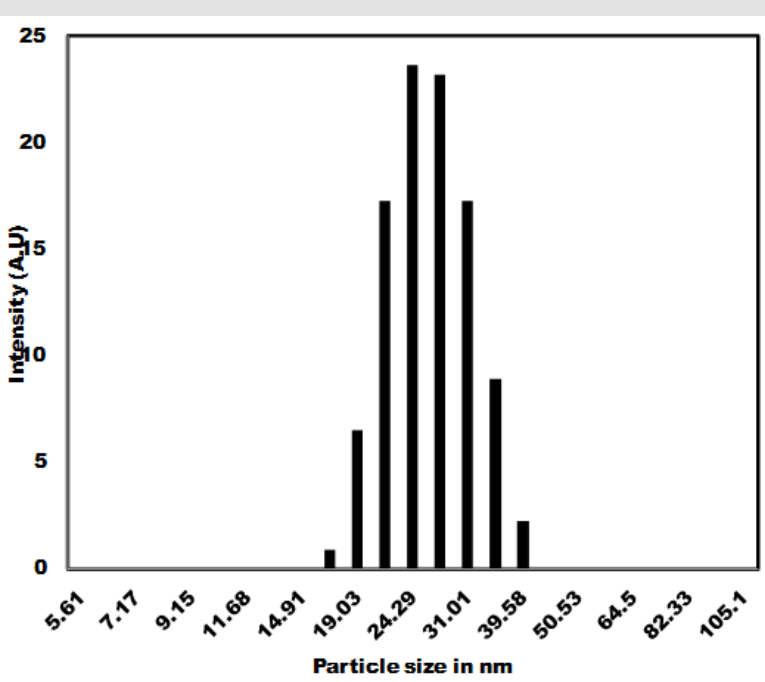

Figure 3: Particle size distribution of as prepared $\mathrm{MnO}_{3}$ Nanoparticles 


\section{Gas Sensing Property}
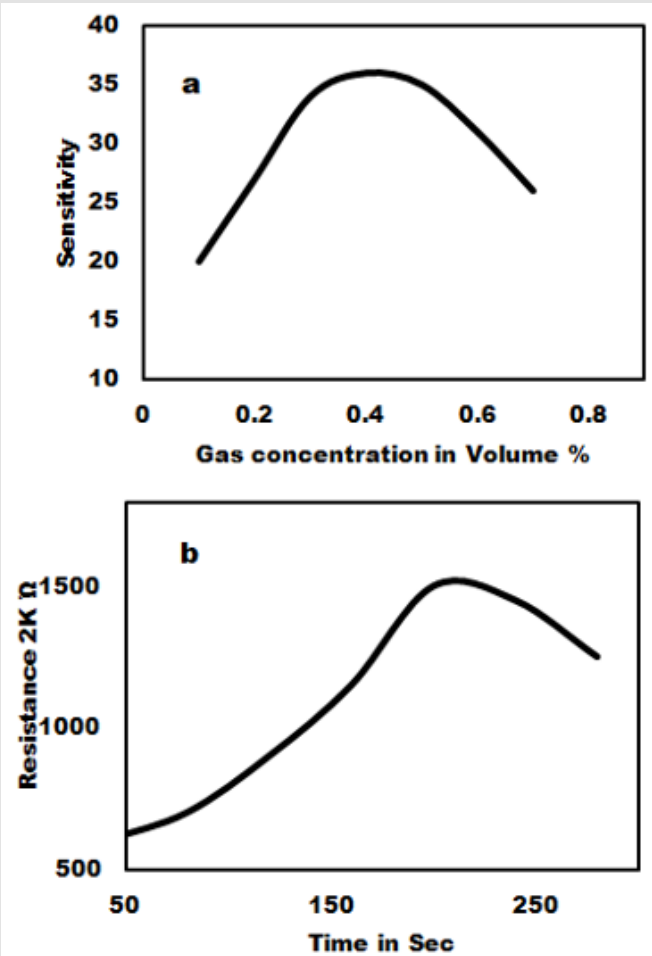

Figure 4: Effect of Gas concentration on the sensitivity of $\mathrm{MoO}_{3}$ Pellet (a) and response time (b).

The ammonia gas sensing studies of as synthesized $\mathrm{MoO}_{3}$ nanoparticles have been carried out and the result is shown in Figure 4 . The gas sensitivity was measured at various temperatures in the range of $100^{\circ} \mathrm{C}$ to $400^{\circ} \mathrm{C}$. Figure 4 a shows that 3 to 6 mole $\%$ shows very good sensitivity and response time. The as prepared $\mathrm{MoO}_{3}$ was mixed with PVA (2 \%) as binder and then pressed into pellets of $1.67 \mathrm{~cm}$ diameter and 0.12-0.25 cm thicknesses under the pressure of 10 tons. These pellets were heated in air at $600 \circ \mathrm{C}$ to remove adhesive. The gas sensitivity sensors were fabricated by pressing the $\mathrm{MoO}_{3}$ nanoparticles into an accurate weight and then a pellet of $10 \mathrm{~mm}$ in diameter and $1 \mathrm{~mm}$ in thickness is formed. The wire embedded as an electrode for sensing the Gas was used and the sensors were mounted into a specially designed Quartz cell. When the sensor absorbs the gas, the redox reaction takes place and it changes the resistance. The reducing gas used in the present study is ammonia. The concentration of ammonia gas was controlled by adjusting the flow rate ratios of target gases to dry air. The sensitivity of the sensors is expressed as the ratio of the air resistance to gas resistance. i.e. $=\mathrm{R}$ air $/ \mathrm{R}$ gas was measured in the temperature range of $200^{\circ} \mathrm{C}$ to $350^{\circ} \mathrm{C}$ in a dynamic flow system. The measurements were performed inside a closed chamber at different temperatures. Gas mixtures were obtained by means of mass flow controllers and driven into the test chamber. A known amount of target gas is mixed in air and injected to the measuring cell at a flow rate of $1000 \mathrm{cc}$ per minute of air, which is a carrier gas. A previous stabilization treatment is performed to reach a stable conductance value before making the test. Ammonia gas was used for the gas sensitivity measurements. For characterization of gas sensing properties the sensor element were placed in a $1000 \mathrm{cc}$, in a temperature controlled gas chamber. A typical gas measurements sequence containing predetermined intervals, in which the sensors were exposed to gas atmospheres. After completion of one sequence, the sensors and measurement cycle was repeated. The resistance response of each sensor structure was transformed into a sensitivity value using commonly used formula for the gases as given as

$$
S=(R \text { air }-R \text { gas }) / R \text { air }
$$

Where $\mathrm{R}$ gas is sensors resistance influenced by the ammonia gas and $\mathrm{R}$ air is the Resistance in the air showing the dynamic response of $\mathrm{MoO}_{3}$ pellet $100 \%$ gas sensors to $1000 \mathrm{ppm}$ ammonia measured at room temperature. The gas sensitivity of $\mathrm{MoO}_{3}$ pellets treated at $700^{\circ} \mathrm{C}$ to $800^{\circ} \mathrm{C}$ exhibit the highest linear decrease of the resistivity with gas concentration. The reaction time is about $20 \mathrm{sec}$ to $30 \mathrm{sec}$ for sample with $\mathrm{MoO}_{3} 100 \%$ sample gas sensor at room temperature. The relative resistivity of the as syntheiszed sensor becomes stable after 20-255 ammonia exposures.

\section{Conclusion}

In conclusion, The $\mathrm{MoO}_{3}$ nanoparticles of narrow size distribution was synthesized and characterized successfully. XRD pattern showed that phase pure $\mathrm{MoO}_{3}$ nanoparticles are formed. TEM study showed that the particle size of $\mathrm{MoO}_{3}$ nanoparticles is about $25 \mathrm{~nm}$. The advantages of this method are simplicity of the process, short duration, energy saving, accessible for auxiliary materials, non-sophisticated equipment and structures with high efficiency. The experimental results confirm that gas sensor based on $\mathrm{MnO}_{3}$ pellets sensitive layer are of great interest for gas detection.

\section{References}

1. Dey A (2018) Materials Science and Engineering: B 229: 206-217.

2. Sui X, Downing JR, Hersam MC, Chen J (2021) Materials today.

3. Wang J, Peng S, Xu L, Zeng W (2020) Front Chem 8: 339.

4. Buono-Core GE, Klahn AH, Castillo C, Muñoz E, Manzur C, et al. (2014) J of Non-Crystalline Solids 387(1): 21-27.

5. Hu B, Mai L, Chen W, Yang F (2009) ACS Nano 3(2): 478-482.

6. Kwak DW, Lei Y, Maric R (2019) Talanta 204: 713-730.

7. Manivel A, Lee GJ, Chen CY, Chen JH, Ma SH, et al. (2015) Mater Res Bull 62: 184-191.

8. Bai S, Chen S, Chen L, Zhang K, Luo R, et al. (2012) Sensors and Actuators B: Chemical 174: 51-58. 
9. Mohamed Maricar S, Sastikumar D, Vanga P, Ashok M (2021) Materials Today 288(1): 129337.

10. Xu K, Liao N, Xue W, Zhou H (2019) Applied Surface Science 509: 144913.

11. Ji H, Zeng W, Li Y (2019) Materials Research Bulletin 118: 110476.

12. Zhu L, Zeng W, Li Y, Zhang H (2018) Materials Letters 229: 269-271.

13. Bai S, Chen S, Chen L, Zhang K, Luo R, et al. (2012) Sens Actuators B 174: 51-58.

14. Liu Y, Yang S, Lu Y, Zakharova GS (2015) Appl Surface Sci 359: 114-119.

15. Chen JS, Cheah YL, Madhavi S, Lou XW (2010) J Phys Chem C 114: 8675 8678.

\section{ISSN: 2574-1241}

DOI: $10.26717 /$ BJSTR.2021.37.005957

Bapurao G Bharate. Biomed J Sci \& Tech Res

(c) (P) This work is licensed under Creative

Submission Link: https://biomedres.us/submit-manuscript.php
16. Wang BB, Zhu K, Feng J, Wu JY, Shao RW, et al. (2016) J Alloys Compd 661: 66-71.

17. Bai S, Chen C, Tian Y, Chen S, Luo R, et al. (2015) Mater Res Bull 64: 252256.

18. T Li, W Zeng, Y Zang, S Hussain (2015) Materials Letters 160: 476-479.

19. Kumar S, Singh A, Singh R, Singh S, Kumar P, et al. (2020) Sensors and Actuators B 325: 128974.

20. Bisht P, Kumar A, Jensen T, Ahmad M, Bella D, et al. (2021) Sensors and Actuators B: Chemical 341: 129953. 